\title{
Differential Effectiveness of Microbially Induced Resistance Against Herbivorous Insects in Arabidopsis
}

\author{
Vivian R. Van Oosten, ${ }^{1,2}$ Natacha Bodenhausen, ${ }^{3}$ Philippe Reymond, ${ }^{3}$ Johan A. Van Pelt, ${ }^{1}$ \\ L. C. Van Loon, ${ }^{1}$ Marcel Dicke, ${ }^{2}$ and Corné M. J. Pieterse ${ }^{1}$ \\ ${ }^{1}$ Graduate School Experimental Plant Sciences, Section Plant-Microbe Interactions, Institute of Environmental Biology, \\ Faculty of Science, Utrecht University, P.O. Box 800.56, 3508 TB Utrecht, The Netherlands; ${ }^{2}$ Graduate School Experimental \\ Plant Sciences, Laboratory of Entomology, Wageningen University, P.O. Box 8031, 6700 EH Wageningen, The Netherlands; \\ ${ }^{3}$ Department of Plant Molecular Biology, University of Lausanne, CH-1015 Lausanne, Switzerland
}

Submitted 9 January 2008. Accepted 24 March 2008.

\begin{abstract}
Rhizobacteria-induced systemic resistance (ISR) and pathogen-induced systemic acquired resistance (SAR) have a broad, yet partly distinct, range of effectiveness against pathogenic microorganisms. Here, we investigated the effectiveness of ISR and SAR in Arabidopsis against the tissuechewing insects Pieris rapae and Spodoptera exigua. Resistance against insects consists of direct defense, such as the production of toxins and feeding deterrents and indirect defense such as the production of plant volatiles that attract carnivorous enemies of the herbivores. Wind-tunnel experiments revealed that ISR and SAR did not affect herbivore-induced attraction of the parasitic wasp Cotesia rubecula (indirect defense). By contrast, ISR and SAR significantly reduced growth and development of the generalist herbivore $S$. exigua, although not that of the specialist $P$. rapae. This enhanced direct defense against $S$. exigua was associated with potentiated expression of the defense-related genes PDF1.2 and HEL. Expression profiling using a dedicated cDNA microarray revealed four additional, differentially primed genes in microbially induced $S$. exigua-challenged plants, three of which encode a lipid-transfer protein. Together, these results indicate that microbially induced plants are differentially primed for enhanced insect-responsive gene expression that is associated with increased direct defense against the generalist $S$. exigua but not against the specialist $P$. rapae.
\end{abstract}

Plants are under constant threat from a multitude of pathogenic and herbivorous attackers. Resistance against microbes and insects can be mediated through defenses that are constitutively present or through defense mechanisms that are induced only upon attack (Dicke and Van Poecke 2002; Van Loon 2000). An important question in plant defense signaling research is how plants are capable of integrating signals induced by pathogenic microorganisms and herbivorous insects into defenses that are specifically active against the invader encountered. The plant hormones salicylic acid (SA), jasmonic acid (JA), and ethylene (ET) are major players in

Corresponding author: C. M. J. Pieterse; E-mail: C.M.J.Pieterse@uu.nl; Fax: +31 30 2532837; Telephone: +31 302536887 .

* The $e$-Xtra logo stands for "electronic extra" and indicates that three supplemental tables are published online. the regulation of signaling networks involved in induced defense (Glazebrook 2001; Kessler and Baldwin 2002; Pieterse and Dicke 2007; Reymond and Farmer 1998; Thomma et al. 2001). The production of SA, JA, and ET varies greatly, depending on the nature of the attacking pathogen or insect. The quantity, composition, and timing of the hormonal blend results in the activation of a specific set of genes that eventually determines the nature of the defense response that is triggered by the attacker encountered (De Vos et al. 2005; Mur et al. 2006). Although there are exceptions (Thaler et al. 2004), in general, it can be stated that pathogens with a biotrophic lifestyle are more sensitive to SA-dependent defense responses, whereas necrotrophic pathogens and herbivorous insects are primarily resisted by defenses dependent on JA, ET, or both (Bostock 2005; Glazebrook 2005).

Induced defense against insect herbivores is triggered upon feeding and consists of two components, direct defense, such as the production of secondary chemicals that act as toxins or feeding deterrents (Howe 2004; Kessler and Baldwin 2002), and indirect defense, such as the production of a blend of volatiles that attract carnivorous enemies of the herbivores (Takabayashi and Dicke 1996; Turlings et al. 1995). Induced direct defense has been demonstrated in many plant species (Kessler and Baldwin 2002). A classic example is the observation that following herbivore attack, tomato leaves systemically accumulate proteinase inhibitor proteins that reduce further insect feeding (Howe 2004). Both JA and ET emerged as important signals in this response (Howe 2004; Von Dahl and Baldwin 2007). JA is also a major phytohormone involved in the induced production of plant volatiles that attract carnivorous enemies of the herbivores (Dicke and Van Poecke 2002; Dicke et al. 1999). SA has been implicated in induced indirect defense against herbivory as well. Herbivores such as spider mites induce the emission of methyl salicylate (MeSA) in many plant species (Ament et al. 2004; De Boer and Dicke 2004), which can lead to the activation of SA-inducible defenserelated genes (Arimura et al. 2000; Kant et al. 2004). Moreover, certain combinations of JA and SA treatments induce a blend of volatiles that is similar to the blend induced by spider mite feeding (Arimura et al. 2000; De Boer and Dicke 2004; Dicke et al. 1999) and attracts carnivorous enemies that can exterminate the herbivore population (Dicke 1999).

In Arabidopsis, induced defense against insect herbivores is very similar to that shown in other plant species. For instance, caterpillars of the specialist herbivore Pieris rapae (small cab- 
bage white) stimulate the production of JA and ET and trigger a systemic defense response that affects insect performance (De Vos et al. 2005, 2006). Moreover, Arabidopsis mutants affected in the JA response are more susceptible to insect feeding (Bodenhausen and Reymond 2007; Ellis et al. 2002; McConn et al. 1997; Mewis et al. 2005, 2006; Reymond et al. 2004; Stintzi et al. 2001; Stotz et al. 2002; Van Poecke and Dicke 2004; Zarate et al. 2007), indicating that JA plays an important role in induced direct defense. Furthermore, Arabidopsis plants infested by caterpillars of $P$. rapae emit volatiles from several major biosynthetic pathways, including terpenoids, MeSA, and green-leaf volatiles. This blend of volatiles attracts adult females of Cotesia rubecula, a specialist parasitic wasp of $P$. rapae, resulting in a fitness increase of the Arabidopsis plant (Van Loon et al. 2000; Van Poecke and Dicke 2004; Van Poecke et al. 2001). Transgenic Arabidopsis S-12 plants with severely reduced wound-inducible JA levels, due to cosuppression of the LIPOXYGENASE2 (LOX2) gene (Bell et al. 1995), and transgenic Arabidopsis NahG plants that cannot accumulate SA, due to expression of the bacterial SA-hydroxylase $(n a h G)$ gene (Delaney et al. 1994), are significantly less attractive to the $C$. rubecula wasps upon herbivory by $P$. rapae than wild-type Col-0 plants (Van Poecke and Dicke 2002). This indicates that both JA and SA are involved in indirect defense in Arabidopsis.

Two forms of induced resistance that are effective against microbial pathogens have been well-characterized, systemic acquired resistance (SAR), which is typically activated upon primary limited infection by a necrotizing pathogen (Durrant and Dong 2004), and induced systemic resistance (ISR), which is typically elicited by specific strains of nonpathogenic rootcolonizing rhizobacteria (Van Loon et al. 1998). SAR is controlled by a signaling pathway that depends on endogenous accumulation of SA and the defense regulatory protein NPR1 (Durrant and Dong 2004) and is associated with the activation of pathogenesis-related $(P R)$ genes, some of which encode proteins with antimicrobial activity (Van Loon et al. 2006). ISR triggered by the nonpathogenic rhizobacterium Pseudomonas fluorescens WCS417r functions independently of SA but requires responsiveness to JA and ET (Pieterse et al. 1996, 1998; Van der Ent et al. 2008; Van Wees et al. 1997). In contrast to SAR, the onset of ISR is not associated with enhanced defense-related gene expression (Verhagen et al. 2004). How- ever, after challenge inoculation, a large set of predominantly JA-responsive genes show a potentiated expression pattern in ISR-expressing leaves, indicating that these genes are sensitized to either respond faster or more strongly, or both, upon pathogen attack. This phenomenon is called "priming" and has been demonstrated to play a role in different types of induced resistance, including SAR (Conrath et al. 2002, 2006). Both ISR and SAR are effective against a broad range of pathogens (Durrant and Dong 2004; Van Loon et al. 1998). However, their ranges of effectiveness overlap only partly. Pathogeninduced SAR is predominantly effective against biotrophic pathogens, whereas rhizobacteria-mediated ISR is predominantly effective against pathogens that are sensitive to JA- and ET-dependent defenses (Ton et al. 2002).

The common involvement of SA, JA, and ET in the regulation of the induced defense responses that are triggered by microbes and insects suggests that the effectiveness of the respective induced resistance responses will overlap, at least partly. However, several studies have shown that activation of SAdependent SAR negatively affects resistance against specific insects (Bostock 2005; Felton and Korth 2000; Pieterse et al. 2001), which is probably caused by the antagonistic effect of SA on JA signaling (Koornneef and Pieterse 2008; Spoel et al. 2003). By contrast, rhizobacteria-mediated ISR in cucumber has been demonstrated to simultaneously reduce bacterial wilt disease, caused by Erwinia tracheiphila, and feeding of the cucumber beetle vector that transmits this disease (Zehnder et al. 2001). To investigate the extent of overlap in effectiveness of induced resistance that is triggered by microorganisms and insect herbivores, the effectiveness of herbivore-induced resistance in Arabidopsis against the microbial pathogens Alternaria brassicicola, Pseudomonas syringae pv. tomato, Xanthomonas campestris pv. armoraciae, and Turnip crinkle virus (TCV) (De Vos et al. 2006) was previously studied. Caterpillar feeding significantly reduced disease caused by Pseudomonas syringae pv. tomato, Xanthomonas campestris pv. armoraciae, and TCV but did not affect the level of resistance to the necrotroph Alternaria brassicicola. Here, we report on a reciprocal study in which the effect of microbially induced resistance (ISR and SAR) in Arabidopsis on direct and indirect defense against two different chewing insects was studied, $P$. rapae, a specialist on crucifers, and the generalist Spodoptera exigua (beet armyworm).
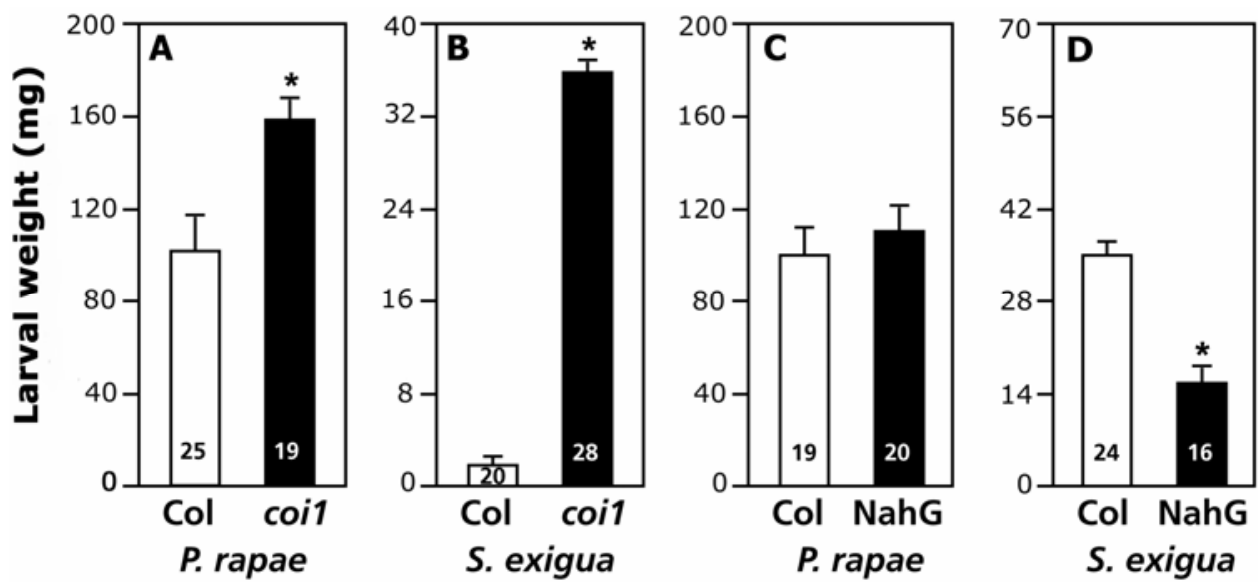

Fig. 1. Performance of Pieris rapae and Spodoptera exigua on Arabidopsis genotypes affected in jasmonic acid or salicylic acid signaling. First-instar larvae were allowed to feed on single plants confined in Magenta vessels with an insect-proof mesh lid. A, and $\mathbf{C}$, The data presented are the average weight of $P$. rapae larvae after 7 days of feeding on Col-0 and coil-16 or NahG plants and B, and D, S. exigua larvae after 10 days of feeding on Col-0 and coil-1 or NahG plants. The data shown are means \pm standard error $(n=16$ to 28$)$ of the weights of the caterpillars 2 days before the first larva started to pupate. Asterisks indicate statistically significant differences $(P<0.05)$ according to Kruskal-Wallis followed by Mann-Whitney U tests in SPSS 11.5 for Windows. The number of caterpillars weighed $(n)$ is given in the bar. Experiments were repeated with similar results. 


\section{RESULTS}

Performance of $P$. rapae and $S$. exigua on Arabidopsis genotypes affected in JA or SA signaling.

In Arabidopsis, ISR and SAR are regulated by JA- and SAdependent signaling pathways, respectively (Durrant and Dong 2004; Pieterse et al. 2002). JA- and SA-dependent defenses have been demonstrated to antagonistically affect insect performance (Bostock 2005). To verify whether the performance of the specialist herbivore $P$. rapae and the generalist herbivore $S$. exigua are, in our experimental setup, affected by either JA or SA signaling, or both, the growth of their larvae was monitored on Arabidopsis genotypes coil and $\mathrm{NahG}$, which are impaired in JA or SA signaling, respectively. To assess the effect of JA signaling on direct defenses against $P$. rapae and $S$. exigua, firstinstar (L1) larvae were placed onto individually confined coil plants, after which their weight was monitored over time. As the larvae stop growing when they start to pupate, only the timepoints until two days before the first larva started to pupate were considered in the assay. Figure $1 \mathrm{~A}$ and $\mathrm{B}$ shows that the fresh weights of the larvae were significantly higher on coil plants than on wild-type Col-0 plants, confirming previous findings (Bodenhausen and Reymond 2007; Reymond et al. 2004). Together, these results indicate that JA-dependent defenses that are mediated by COI1 negatively affect the growth of both $P$. rapae and $S$. exigua larvae. To assess the effect of SA on direct defenses against $P$. rapae and $S$. exigua, larval performance was monitored on Col-0 and SA-nonaccumulating NahG plants. Figure $1 \mathrm{C}$ shows that growth of $P$. rapae larvae was not affected by the $n a h G$ transgene. By contrast, growth of $S$. exigua larvae was significantly reduced on NahG plants (Fig. 1D), indicating that the absence of SA in NahG negatively affected growth of the generalist but not that of the specialist herbivore.

\section{Effect of ISR and SAR}

on the performance of $P$. rapae and $S$. exigua.

ISR and SAR are effective against a wide range of pathogens. In Arabidopsis, it has been shown that ISR is predominantly effective against pathogens that are sensitive to JA- and ET-dependent defenses, whereas SAR is mainly effective against pathogens that are sensitive to SA-dependent defenses (Ton et al. 2002). Because both $P$. rapae and $S$. exigua can be affected by JA-dependent defense responses, we hypothesized that induction of rhizobacteria-mediated ISR would enhance the level of resistance against both herbivores. Because SA has been shown to antagonize JA signaling (Koornneef and Pieterse 2008), we hypothesized that induction of SAR would decrease the basal level of insect resistance. To investigate the effect of ISR and SAR on P. rapae and S. exigua performance, L1 larvae were placed on individually confined ISR- and SAR-expressing plants and were monitored until pupation. ISR was induced by growing plants in soil with ISR-inducing Pseudomonas fluorescens WCS417r bacteria. SAR was induced by infiltrating three lower leaves with avirulent Pseudomonas syringae pv. tomato DC3000 (avrRpt2) 3 days prior to transfer of the caterpillars to the leaves. Figure $2 \mathrm{~A}$ shows that feeding by $P$. rapae caterpillars on either uninduced control plants or ISR- or SAR-expressing plants did not result in significant differences in the average weight of the larvae. Moreover, neither ISR nor SAR had an effect on the average time to pupation (Fig. 2C). By contrast, both ISR and SAR significantly reduced the weight gain of $S$. exigua larvae (Fig. 2B), resulting in a 28 to $32 \%$ lower weight of the larvae two days before the first larvae started to pupate. Reduced growth of S. exigua larvae on ISRand SAR-expressing plants coincided with a prolonged time until pupation, although this effect was only significant for the larvae feeding on ISR-expressing Arabidopsis (Fig. 2C; ISR, $P=0.018$; SAR, $P=0.096$ ). These results indicate that microbially induced ISR and SAR are associated with enhanced resistance against feeding by the generalist herbivore $S$. exigua but not against feeding by the specialist herbivore $P$. rapae.

\section{ISR and SAR are associated with potentiated expression of $P D F 1.2$ and $H E L$ upon herbivory.}

As mentioned above, both ISR and SAR are associated with priming for enhanced defense-related gene expression, resulting in a potentiated activation of specific gene sets upon pathogen challenge (Conrath et al. 2006; Verhagen et al. 2004). Previously, herbivory by the specialist $P$. rapae and the generalist Spodoptera littoralis (Egyptian cotton worm) have been demonstrated to activate similar sets of predominantly JA-responsive genes in Arabidopsis (Reymond et al. 2004). To investigate whether the reduced performance of $S$. exigua on ISRand SAR-expressing plants is associated with priming for en-
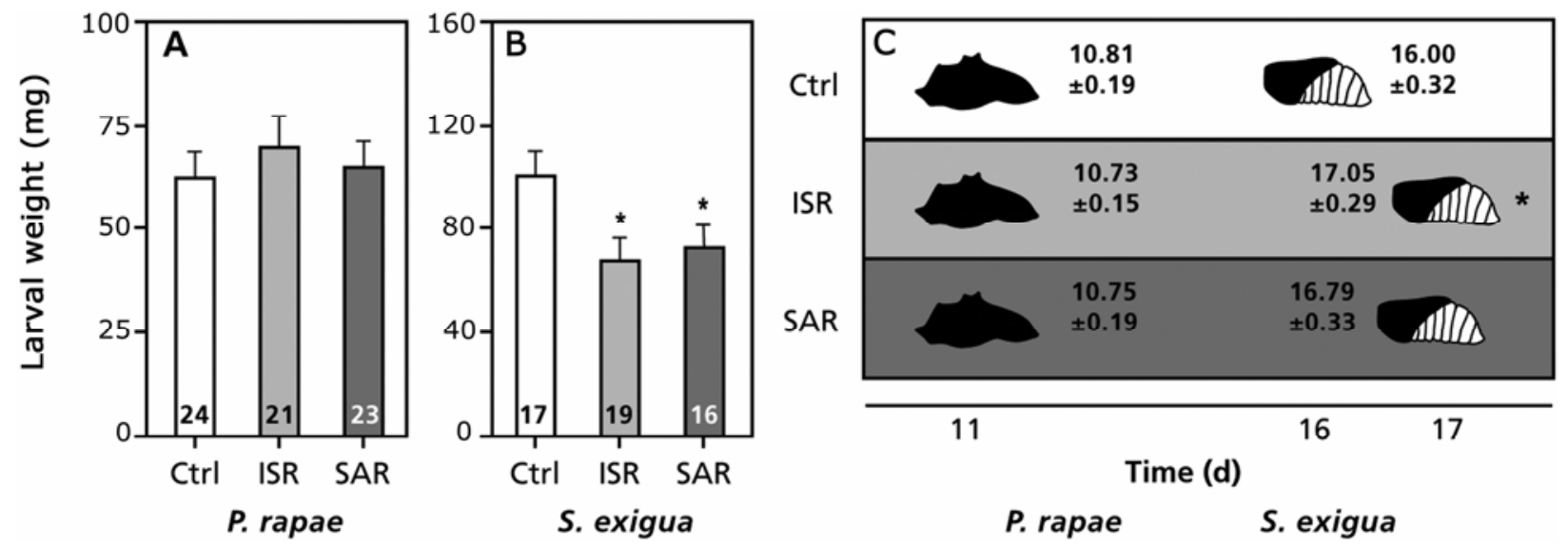

P. rapae

S. exigua

Fig. 2. Performance of Pieris rapae and Spodoptera exigua on Arabidopsis Col-0 plants expressing microbially induced induced systemic resistance (ISR) or systemic acquired resistance (SAR). First-instar larvae were placed on individually confined plants that were either uninduced (Ctrl) or expressing ISR or SAR, after which they were monitored until pupation. ISR was induced by growing the plants in soil containing ISR-inducing Pseudomonas fluorescens WCS417r bacteria. SAR was induced by preinfecting three leaves per plant with avirulent Pseudomonas syringae pv. tomato DC3000 (avrRpt2). Shown are the weights of A, P. rapae larvae at day 7 and B, S. exigua larvae at day 12 . The data shown are means \pm standard error (SE) of the weights of the caterpillars 2 days before the first larva started to pupate. C, Average number of days $( \pm \mathrm{SE})$ by which the larvae started to pupate in the experiments shown in A and B. Asterisks indicate statistically significant differences $(P<0.05)$ based on Kruskal-Wallis followed by Mann-Whitney $\mathrm{U}$ tests $(\mathrm{A}$ and B) and One-way analysis of variance followed by a least significant difference post hoc test $(C)$ in SPSS 11.5 for Windows. The number of caterpillars weighed ( $n$ ) is given in the bar. Each experiment was performed at least twice with similar results. 
hanced herbivore-induced gene expression, the expression of the JA and ET-responsive genes PDF1.2 and HEL in uninduced control plants and in ISR- and SAR-expressing plants was analyzed (Fig. 3). Herbivory by $P$. rapae or $S$. exigua resulted in a low but detectable increase in PDF1.2 transcript levels three days after infestation, whereas $H E L$ mRNA levels remained virtually unchanged. In comparison with uninduced control plants, expression of either ISR or SAR had no clear effect on the $P$. rapae-induced levels of $P D F 1.2$ and $H E L$ mRNA. By contrast, expression of ISR and SAR resulted in a strong potentiated level of expression of PDF1.2 and HEL in response to $S$. exigua feeding. These results indicate that ISRand SAR-expressing plants are primed to express PDF1.2 and $H E L$ to a much higher level upon herbivory by the generalist $S$. exigua but not upon feeding by the specialist $P$. rapae.

\section{Microarray analysis of herbivore-induced gene expression.}

To further validate the differentially primed expression pattern of S. exigua- and P. rapae-induced genes in ISR- and SARexpressing plants and to identify additional insect-responsive genes that show a primed expression pattern in microbially induced plants, the experiment illustrated in Figure 3 was repeated three more times. From these replicated experiments, plant material was harvested for Northern blot and microarray analysis. Northern blot analysis confirmed the potentiated expression pattern of PDF1.2 in S. exigua-infested ISR- and SAR-expressing plants and the lack of it in $P$. rapae-infested plants (data not shown).
To identify additional primed genes, microarray experiments were performed with a dedicated cDNA microarray containing 279 cDNAs representing 222 unique genes, consisting of 111 insect-induced genes, 94 stress- and pathogen-induced genes, and 17 housekeeping genes (Bodenhausen and Reymond 2007). Microarray hybridizations were performed with RNA probes from three biological replicates of leaf material that was harvested from uninduced or ISR-expressing plants 2 days after challenge with $S$. exigua or $P$. rapae. RNA probes from unchallenged but otherwise similarly treated plants were used as reference probes on all microarrays. All three independent biological replicates were hybridized separately to a microarray. Hence, the expression ratios are the average of three independent measurements. The microarray experiments revealed 53 S. exigua-responsive and $75 P$. rapae-responsive genes that met our selection criteria (described below and in Supplemental Tables S1 and S2). All S. exigua-responsive genes were also responsive to $P$. rapae feeding, confirming previous findings (Reymond et al. 2004). The selection for genes with a potentiated expression pattern in $S$. exigua-challenged, ISR-expressing plants revealed five genes, including PDF1.2 (Fig. 4; Table $1)$. Among the primed genes were three lipid-transfer protein genes and one cystein protease gene. HEL showed a mild potentiated expression pattern as well (Hevein-related protein precursor [PR4]) but did not meet our selection criteria. Interestingly, none of the ISR-primed, S. exigua-responsive genes showed a primed expression pattern in ISR-expressing plants that were challenged with $P$. rapae, confirming our notion that

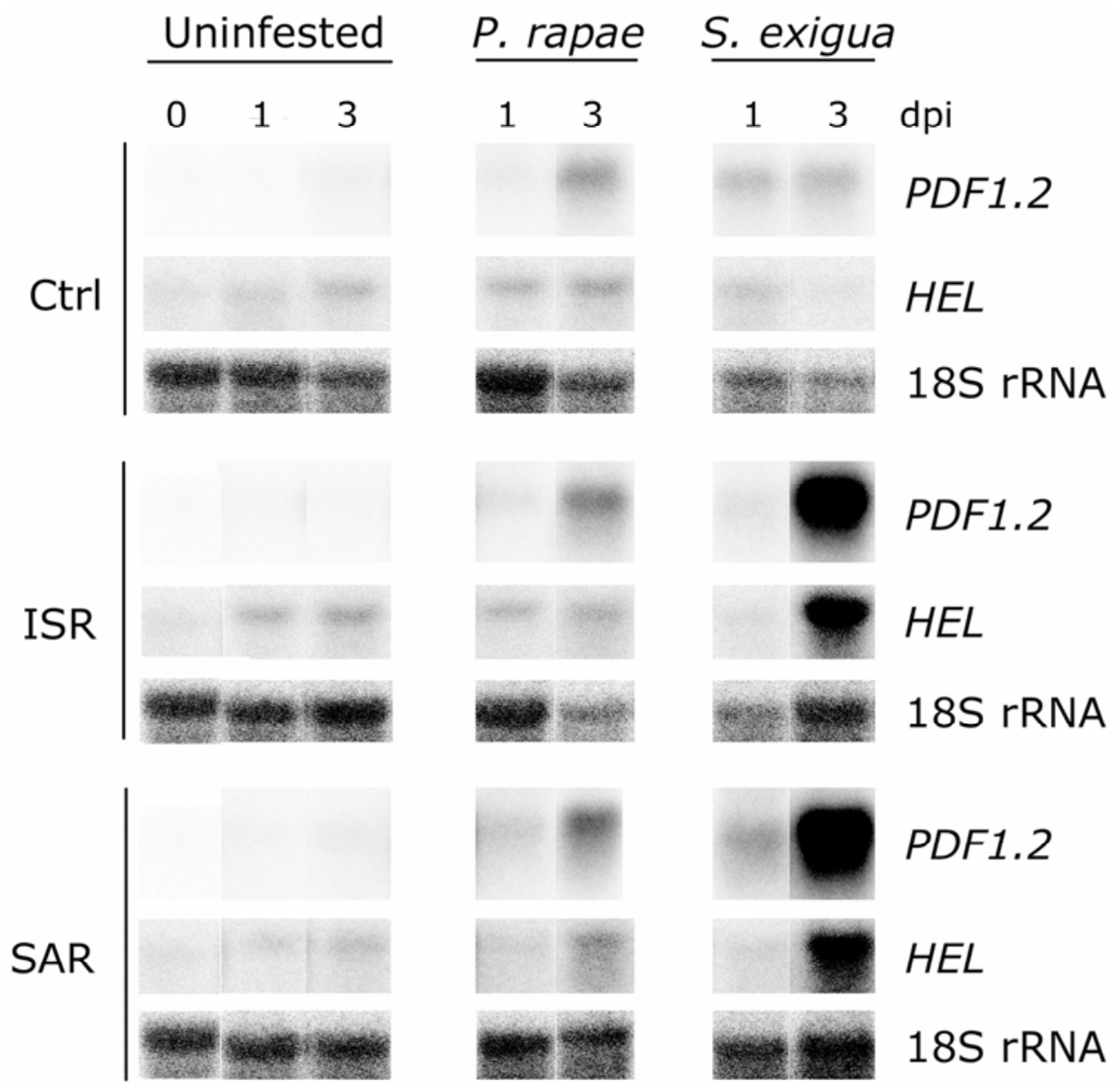

Fig. 3. Induced systemic resistance (ISR)- and systemic acquired resistance (SAR)-mediated priming of herbivore-induced $P D F 1.2$ and $H E L$ gene expression. Northern blot analysis of herbivore-induced PDF1.2 and HEL transcript levels in Arabidopsis Col-0 plants that were uninduced (Ctrl) or expressing microbially induced ISR or SAR. Leaf tissues were harvested from uninfested plants and from infested plants after feeding by first-instar larvae of Pieris rapae or Spodoptera exigua. Equal loading of RNA samples was checked using a probe for $18 \mathrm{~S}$ rRNA. dpi = days postinfestation. 
ISR-expressing plants are differentially primed for augmented $S$. exigua- and $P$. rapae-responsive gene expression.

In addition to the identified $S$. exigua-induced genes with significantly enhanced expression patterns in ISR-expressing plants, six $P$. rapae-responsive genes were identified as being repressed in ISR-expressing plants (data not shown). These genes encode a glutathione-S-transferase (At2g29450), a putative myrosinase-binding protein (At3g16420), a jacalin lectin family protein (At3g16410), a hydroxyjasmonate sulfotransferase (At5g07010), an indole 3-acetic acid-Ala hydrolase (At1g51760), and the senescence-associated protein SAG21 (At4g02380). Interestingly, JAZ2 (At1g74950), encoding one of the ZIM domain-containing JAZ proteins that were previously shown to act as repressors of JA-responsive genes (Chini et al. 2007; Chung et al. 2008; Thines et al. 2007), was significantly repressed in ISR-expressing plants upon challenge by both $P$. rapae and $S$. exigua.

\section{Effect of ISR and SAR}

on herbivore-induced indirect defense.

Volatiles that are produced upon insect feeding play an important role in the indirect defense of plants through the attrac- tion of carnivorous enemies that attack the herbivores. The tritrophic interaction between Arabidopsis, the insect herbivores $P$. rapae and $S$. exigua, and the parasitic wasp $C$. rubecula is an established model to study herbivore-induced indirect defense (Van Poecke et al. 2001, 2003). Using transgenic Arabidopsis S-12 and NahG plants, both JA and SA have been shown to play a role in the herbivore-induced attraction of the parasitic wasp C. rubecula (Van Poecke and Dicke 2002). Interestingly, herbivore-induced volatiles have been implicated in priming for enhanced defense (Engelberth et al. 2004; Frost et al. 2008; Kessler et al. 2006; Paschold et al. 2006; Ton et al. 2006). Because of the role of priming in ISR and SAR, we hypothesized that both types of microbially induced resistance would affect the indirect defense response that is triggered upon insect herbivory.

To investigate the effect of ISR and SAR on the indirect defense response of Arabidopsis, the attraction of $C$. rubecula to ISR- and SAR-expressing plants was monitored upon feeding by $P$. rapae or $S$. exigua. To this end, L1 larvae of $P$. rapae or $S$. exigua were allowed to feed for 24 or $72 \mathrm{~h}(P$. rapae or $S$. exigua, respectively) on control, ISR-, or SAR-expressing plants. Quantification of the damage caused by either P. rapae

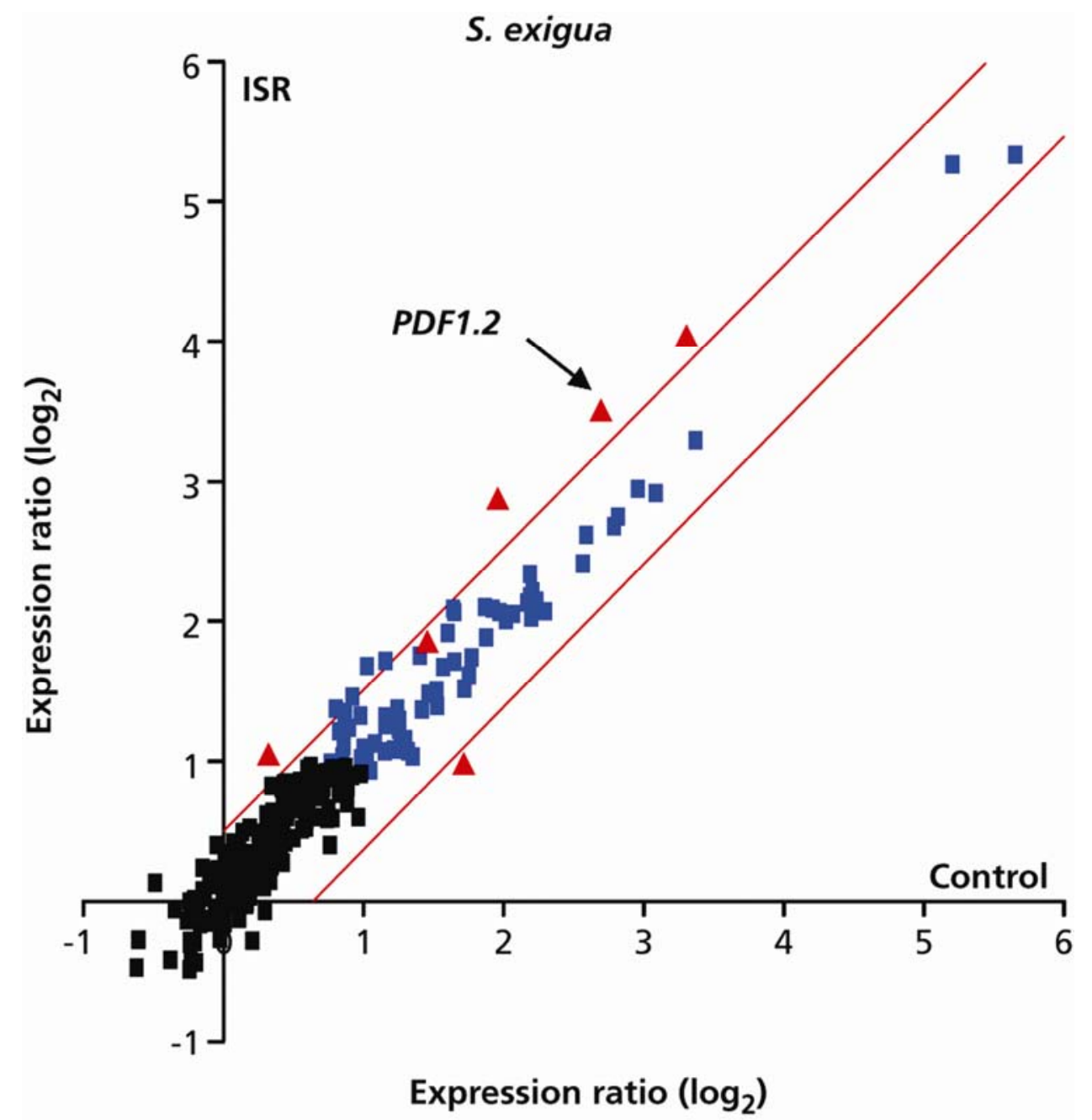

Fig. 4. Microarray analysis of Spodoptera exigua-responsive genes in uninduced and induced systemic resistance (ISR)-expressing Arabidopsis plants. Pairwise comparisons of relative changes in gene expression in uninduced control and ISR-expressing Arabidopsis Col-0 plants two days after challenge with $S$. exigua. Mean expression ratios calculated from experiments comparing challenged and unchallenged control plants (three biologically independent replicates) are plotted against mean expression ratios between challenged and unchallenged plants that expressed Pseudomonas fluorescens WCS417r-mediated ISR (three biologically independent replicates). Genes that showed no changes in gene expression are represented by black squares, S. exigua-responsive genes are represented by blue squares. Red triangles represent $S$. exigua-responsive genes that show a potentiated expression pattern in ISR-expressing plants. Red lines mark the borders of the 1.5 -fold cut-off value. 
or $S$. exigua during the short feeding period revealed that the extent of damage did not significantly differ between uninduced, ISR-, and SAR-expressing plants (data not shown). Naive female $C$. rubecula wasps were individually released in a windtunnel setup (Van Poecke et al. 2001) and were given the choice between two odor sources in different combinations. Odor sources comprised control, ISR-, or SAR-expressing plants, with or without caterpillar damage. Subsequently, the flight behavior of the wasps was observed and the number of first landings on one of the odor sources was recorded. First landings of the wasps on other parts of the wind tunnel were recorded as "no choice." The number of first landings on a given odor source reflects the degree of attractiveness to the parasitic wasp. Control, ISR-, and SAR-expressing Col-0 plants without caterpillar damage were equally unattractive to C. rubecula, as there were relatively few wasps $(<30 \%)$ that responded to the offered plants (data not shown). The two- choice tests in which herbivore-damaged plants were offered resulted in a much greater response of the $C$. rubecula wasps (57 to 79\%). Uninduced control plants infested with either $P$. rapae or $S$. exigua attracted significantly more parasitic wasps than undamaged control plants (Fig. 5, Ctrl vs. Ctrl+P.r. and Ctrl vs. Ctrl+S.e.), indicating that herbivory by $P$. rapae or $S$. exigua larvae resulted in enhanced attractiveness of the plant to the wasps, confirming previous findings (Van Poecke et al. 2003). When caterpillar-damaged control plants were compared with equally damaged ISR- or SAR-expressing plants, no statistically significant differences were observed in any of the combinations. Similarly, the total number of parasitoid wasps responding to any of the two odor combinations was not significantly different among experiments. These results indicate that neither ISR nor SAR significantly affect the indirect defense response of Arabidopsis that is triggered upon feeding by either the specialist $P$. rapae or the generalist $S$. exigua.

Table 1. Arabidopsis genes showing primed expression in induced systemic resistance (ISR)-expressing plants upon challenge with Spodoptera exigua but not upon challenge with Pieris rapae

\begin{tabular}{|c|c|c|c|c|c|c|c|}
\hline \multirow[b]{2}{*}{ AGI code } & \multirow[b]{2}{*}{ Description } & \multicolumn{3}{|c|}{ P. rapae } & \multicolumn{3}{|c|}{ S. exigua } \\
\hline & & Ctrl & ISR & $P$ value $^{\mathrm{b}}$ & Ctrl & ISR & $P$ value $^{\mathrm{b}}$ \\
\hline At3g22600 & Lipid transfer protein (LTP) & $5.5^{*}$ & $5.7 *$ & 0.865 & $4.0 *$ & $7.1 *$ & 0.014 \\
\hline At3g22620 & Lipid transfer protein (LTP) & $3.8 *$ & $3.4^{*}$ & 0.714 & $2.7 *$ & $3.6^{*}$ & 0.045 \\
\hline At $4 \mathrm{~g} 11320$ & Cysteine proteinase (similar to RD21a) & $12.5 *$ & $15.9 *$ & 0.511 & $10.2 *$ & $15.8^{*}$ & 0.662 \\
\hline At5g44420 & Plant defensin protein (PDF1.2a) & $4.7 *$ & $4.7 *$ & 0.599 & $6.7 *$ & $10.9 *$ & 0.031 \\
\hline At5g59310 & Lipid transfer protein 4 (LTP4) & 1.7 & $2.2 *$ & 0.762 & 1.3 & $2.0 *$ & 0.002 \\
\hline
\end{tabular}

${ }^{a}$ Relative changes in gene expression were measured in uninduced control (Ctrl) and rhizobacteria-treated (ISR) Arabidopsis plants $48 \mathrm{~h}$ after challenge with $P$. rapae or $S$. exigua. ISR-primed genes are genes with a significantly different expression or with a $>1.5$-fold difference in expression between uninduced and ISR-expressing plants after herbivore challenge in at least two out of three replicates. Statistical significance in differences $(P<0.05)$ were assessed for the mean $\log _{2}$-transformed expression ratios of genes from uninduced, herbivore-challenged plants vs. those of genes from ISR-expressing, herbivorechallenged plants. Presented in bold are mean expression ratios with statistically significant or $>1.5$-fold difference between ISR-expressing and uninduced plants after insect feeding. Asterisks denote the significant difference $(P<0.05)$ of the mean $\log _{2}$-transformed expression ratios of genes from challenged plants in comparison with genes from unchallenged plants.

${ }^{\mathrm{b}}$ Control vs. ISR.

A

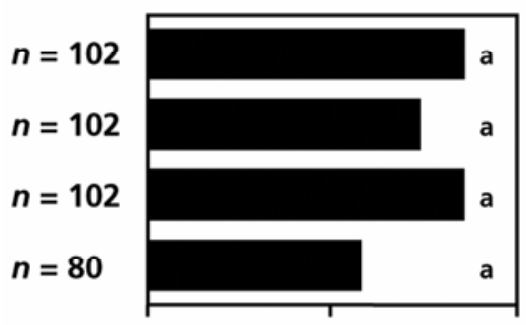

B

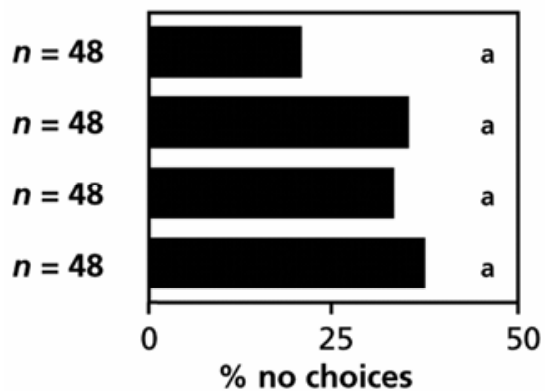

P. rapae

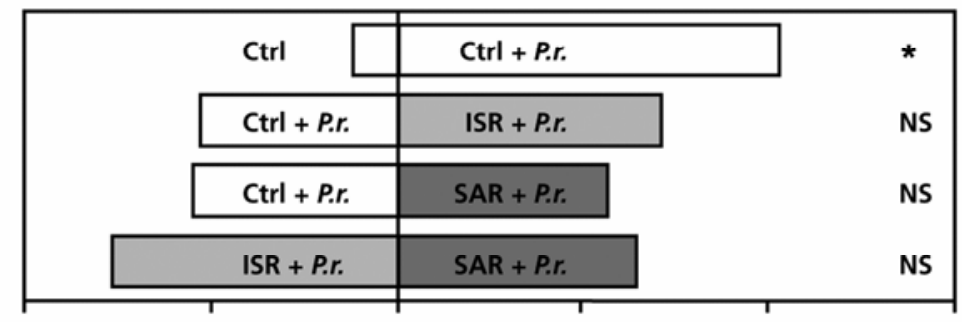

S. exigua

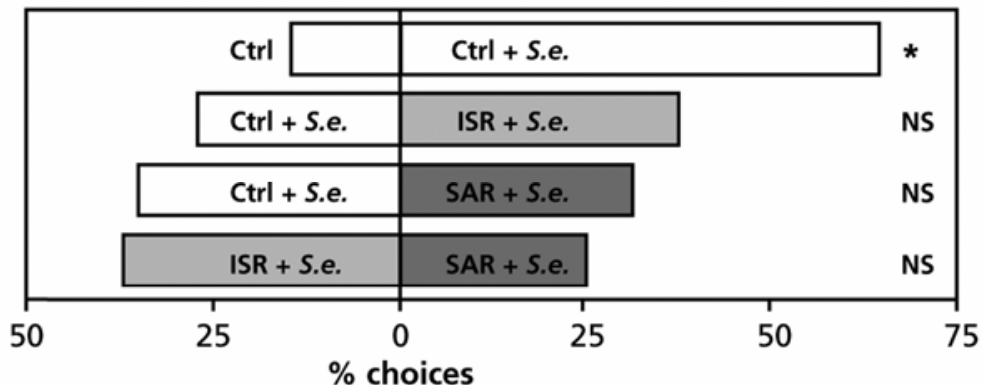

Fig. 5. Responsiveness of the parasitic wasp Cotesia rubecula to herbivore-infested induced systemic resistance (ISR)- and systemic acquired resistance (SAR)-expressing Arabidopsis plants in a two-choice flight setup. Individual female C. rubecula wasps were offered two odor sources in a wind-tunnel setup. Each odor source consisted of 15 Arabidopsis plants that were either uninduced (Ctrl) or expressing microbially induced ISR or SAR, with or without feeding damage caused by Pieris rapae (P.r.) or Spodoptera exigua (S.e.). The number of landings on each odor source was recorded as "choice." When the parasitoid wasp did not land on an odor source, this was noted as "no-choice." The figure shows the percentage of responding and nonresponding wasps. Differences in nonresponsiveness between the odor combinations were tested using a contingency table. Similar letters indicate that there were no statistically significant differences $(P<0.05)$. The differences in responsiveness per odor combination were analyzed with a Chi-square test in SPSS 11.5 for Windows. Asterisks indicate statistically significant differences $(P<0.001)$. NS = nonsignificant differences $(P<0.05), n=$ number of wasps tested. 


\section{DISCUSSION}

The signaling events that occur between perception of microbial or insect-derived elicitors and the subsequent activation of defense responses are relatively well-studied, especially for well-defined types of induced resistance such as pathogeninduced SAR, rhizobacteria-mediated ISR, the wound response, and the response as triggered upon insect herbivory (Dicke and Van Poecke 2002; Durrant and Dong 2004; Howe 2004; Kessler and Baldwin 2002; Pieterse et al. 2002). However, little is known about the spectrum of effectiveness of the different types of induced resistance that is subsequently expressed. Is herbivore-induced resistance specifically effective against insect herbivores or does it also affect pathogens? Is microbially induced resistance specifically directed against microbial pathogens or are insect herbivores affected as well? In the past, a number of studies investigated the effect of microbially induced defense on insects and vice versa (Stout et al. 2006). However, due to the large variety in the choice of plant, insect, and pathogen species, the results varied, and it was difficult to draw general conclusions about the response of one plant against multiple attackers. Therefore, we decided to address the above-mentioned questions in a single plant species, Arabidopsis thaliana. To gain insight in the complexity of the defense signaling network of Arabidopsis, the signal signature and whole-genome transcript profile of Arabidopsis was monitored upon attack by pathogens and insects with different modes of action (De Vos et al. 2005). In addition, the effectiveness of herbivore-induced resistance in Arabidopsis against the microbial pathogens Alternaria brassicicola, Pseudomonas syringae pv. tomato, Xanthomonas campestris pv. armoraciae, and TCV was investigated (De Vos et al. 2006). Here, we performed a reciprocal study in which the effect of two types of microbially induced resistance (ISR and SAR) on direct and indirect defense against the insect herbivores $P$. rapae and $S$. exigua was investigated. We demonstrate that ISR and SAR have no effect on direct defense against feeding by the specialist $P$. rapae. However, both ISR and SAR negatively affect growth and development of $S$. exigua, and this effect on direct defense against this generalist herbivore is associated with priming for enhanced expression of a specific set of $S$. exigua-responsive genes. In addition, we show that ISR and SAR have no effect on the indirect defense response that is triggered upon herbivory by either $P$. rapae or $S$. exigua.

\section{Direct insect defense.}

Analysis of insect performance on Arabidopsis mutants and transgenics that are affected in JA signaling revealed an important role for JA in direct insect defense in this plant species. Herbivorous insects such as $P$. rapae, S. exigua, S. littoralis, Myzus persicae (green peach aphid), and Bradysia impatiens (common fungus gnat) were shown to be negatively affected by JA-dependent defenses (Bodenhausen and Reymond 2007; Chung et al. 2008; McConn et al. 1997; Mewis et al. 2005; Reymond et al. 2004; Stintzi et al. 2001; Stotz et al. 2002). In this study, it was demonstrated that $P$. rapae and $S$. exigua larvae perform better on mutant coil plants, confirming that JAdependent defense responses contribute to direct defense against these caterpillars.

Arabidopsis mutants and transgenics that are compromised in SA-dependent defense responses have been shown to exhibit enhanced resistance against feeding by the cabbage looper Trichoplusia ni (Cui et al. 2002), the Egyptian cotton worm $S$. littoralis (Stotz et al. 2002), and the beet armyworm S. exigua (Cipollini et al. 2004; Mewis et al. 2005). Similarly, this study demonstrated that $S$. exigua performance is significantly reduced on SA-nonaccumulating NahG plants (Fig. 1), indicating that, in wild-type Arabidopsis plants, SA signaling promotes susceptibility to insect feeding. In many studies SA signaling has been demonstrated to act antagonistically on JA-dependent signaling (Dicke and Van Poecke 2002; Koornneef and Pieterse 2008; Pieterse et al. 2001; Spoel et al. 2007). Therefore, it is plausible that the observed enhanced resistance to $S$. exigua feeding in NahG plants is caused by the fact that the antagonistic effect of SA on JA signaling is relieved in this genotype.

In contrast to $S$. exigua, $P$. rapae larvae performed similarly on wild-type Col-0 and NahG plants. Apparently, the enhanced JA response in NahG plants had no effect on the level of resistance against this herbivore. This may be caused by the fact that $P$. rapae is less sensitive to JA-dependent defenses than generalists such as S. exigua (Fig. 1) (Bodenhausen and Reymond 2007). P. rapae is a specialist herbivore that has been reported to feed on many Brassicaceous species in the field, including Arabidopsis (Yano and Ohsaki 1993), and to be well adapted to the induced defenses of crucifers. In wild radish for instance, growth of $P$. rapae larvae was not affected by defenses induced by insect-damage and JA application while the generalist $S$. exigua was negatively affected (Agrawal et al. 1999). In line with this observation, $P$. rapae was demonstrated to detoxify deleterious Arabidopsis-derived glucosinolate compounds in its gut (Wittstock et al. 2004), further illustrating that specialist insects have adapted to the resistance mechanisms of their host plants. Although it was shown that $P$. rapae is not insensitive to all induced defenses in Arabidopsis (Agrawal and Kurashige 2003; De Vos et al. 2006), the difference in sensitivity to JAmediated defenses between $P$. rapae and $S$. exigua seem to be due to a better adaptation of $P$. rapae to Brassicaceous plants.

\section{ISR, SAR, and direct insect defense.}

In view of the effects of JA and SA signaling on direct defense against herbivory, we expected that both ISR and SAR would affect the level of resistance against insect herbivores. Only a limited number of studies investigated the effect of rhizobacteria-mediated ISR against insects. For example, Zehnder and coworkers (2001) demonstrated that ISR triggered by nonpathogenic rhizobacterial strains resulted not only in resistance against bacterial wilt caused by the pathogen Erwinia tracheiphila but also reduced feeding by the cucumber beetles Diabrotica undecimpunctata and Acalymma vittata that are vectors of this pathogen. ISR against cucumber beetle feeding was associated with reduced concentrations of cucurbitacin, a secondary plant metabolite and powerful beetle-feeding stimulant. A number of studies investigated the effect of SAR triggered by avirulent pathogens on the performance of herbivorous insects. Depending on the plant-insect combination, the effect of SAR on insect performance was either positive, negative, or neutral, indicating that the effect of SAR is not easy to predict (Stout et al. 2006).

In this study, we demonstrated that neither ISR nor SAR had a significant effect on the level of resistance of Arabidopsis against $P$. rapae feeding (Fig. 2). These findings are in line with our observation that specialist $P$. rapae larvae are relatively insensitive to JA-dependent defenses and, therefore, also to the effect that SA exerts on JA signaling. Surprisingly, both ISR and SAR significantly reduced growth of $S$. exigua (Fig. 2B). Moreover, ISR also significantly delayed the onset of pupation (Fig. 2C). For ISR, the negative effect on S. exigua larval development was to be expected, because this type of induced resistance is effective against attackers that are sensitive to JA-dependent defenses (Ton et al. 2002). However, because of the antagonistic effect of SA on JA signaling, we expected SAR-expressing plants to have enhanced susceptibility to $S$. exigua feeding, which was clearly not the case. Previously, Cui and associates (2005) demonstrated that coronatine, a Pseudo- 
monas syringae-derived functional and structural mimic of JA, induces resistance against the generalist herbivore Trichoplusia $n i$ (Cui et al. 2005). Hence, it is tempting to speculate that the enhanced resistance against $S$. exigua in SAR-expressing plants is caused by the coronatine that is produced by the SAR-inducing agent Pseudomonas syringae pv. tomato DC3000 (avrRpt2).

Interestingly, the negative effect of ISR and SAR on $S$. exigua performance (and the lack of it on P. rapae) correlated with a potentiated expression pattern of the defense-related genes PDF1.2 and HEL in microbially induced, herbivorechallenged plants (Fig. 3). Again, for ISR the augmented expression of PDF1.2 and HEL was not unexpected, because this type of induced resistance is primarily based on priming for JA and ET-dependent defenses (Verhagen et al. 2004); but for SAR, this result could not be readily explained. In the past, the role of priming during SAR was mainly focused on SA-responsive genes such as $P A L$ and the SAR marker gene PR-1 (Conrath et al. 2002, 2006). Both genes show a potentiated expression pattern in SAR-expressing plants upon challenge inoculation with SA-inducing pathogens or upon challenge with chemical elicitors of the SA response (e.g., benzothiadiazole [BTH] and 2-6-dichloro isonicotinic acid). However, little is known about the expression pattern of JA and ET-responsive genes in SAR-expressing plants upon challenge with biological or chemical elicitors of the JA response. Our data clearly show that induction of SAR by avirulent Pseudomonas syringae pv. tomato DC3000 (avrRpt2) is associated with priming for enhanced expression of $P D F 1.2$ and $H E L$ upon feeding by $S$. exigua. Because induction of SAR by predisposal infection with avirulent Pseudomonas syringae pv. tomato DC3000 (avrRpt2) not only results in enhanced SA levels but also in increased production of both JA and ET (De Vos et al. 2005), the potentiated expression pattern of PDF1.2 and HEL may be associated with the pathogen-induced increase in the level of JA and ET. Recently, Truman and associates (2007) demonstrated that the systemic transcriptional response of Arabidopsis upon infection by avirulent Pseudomonas syringae shares high overlap with local herbivory and wounding responses, corroborating our finding that SAR-expressing tissues are primed for enhanced defense against insect feeding.

Microarray analysis revealed four additional genes that show a primed expression pattern in ISR-expressing plants upon herbivory by $S$. exigua and not upon feeding by $P$. rapae. Three of these ISR-primed genes (At3g22600, At5g59310, and At3g22620) encode a lipid transfer protein (LTP). The Arabidopsis genome contains more than 15 LTP-encoding genes (Arondel et al. 2000), which are expressed during a wide range of biotic or abiotic stresses. The precise function of LTP in plants is still unknown, although most of the evidence points to a role in plant defense (García-Olmedo et al. 1995; Kader 1997; Segura et al. 1993). Interestingly, the LTP-encoding gene DIR1 (At5g48485) was previously shown to be required for SAR signal transduction (Maldonado et al. 2002). It is, therefore, tempting to speculate that the identified LTP play a role in induced defense signaling. The fourth ISR-primed gene (At4g11320) encodes a cystein protease-like protein with similarity to cysteine protease RD21 (Yamada et al. 2001), which is a member of the papain family of cystein proteases that have been shown to possess anti-insect properties (Konno et al. 2004). Of these additional four ISR-primed genes, only one LTP-encoding gene (At2g22600) has been demonstrated to be JA-responsive (De Vos et al. 2005). Hence, induction of rhizobacteria-mediated ISR does not only prime for certain JA and ET-responsive genes but also for genes that are regulated in a so-far unknown manner.
ISR, SAR, and indirect insect defense.

Previously, it was shown that the Arabidopsis genotypes S12 and NahG are both affected in the ability to attract $C$. rubecula (Van Poecke and Dicke 2002), suggesting a role for both $\mathrm{JA}$ and SA in this induced indirect defense response. Because ISR and SAR are associated with priming for enhanced JAand ET- or SA-dependent defense responses (Conrath et al. 2006), we expected herbivore-damaged ISR- and SAR-expressing plants to be more attractive for $C$. rubecula wasps than herbivore-damaged control plants. However, neither ISR nor SAR had a significant effect on the attraction of $C$. rubecula wasps to Arabidopsis plants that were infested by either $P$. rapae or S. exigua (Fig. 5). It must, therefore, be concluded that neither of the two types of microbially induced resistance have a significant effect on the herbivore-induced indirect defense response in Arabidopsis.

ISR- and SAR-expressing plants are primed for enhanced expression of $S$. exigua-responsive genes. Although this priming phenomenon was associated with enhanced direct defense against $S$. exigua, it did not result in an increased attractiveness to the parasitic wasps, suggesting that the augmented defense response does not affect volatile synthesis. This observation is in agreement with the hypothesis that there may be a negative interaction between direct and indirect defense (Dicke and Van Poecke 2002). Alternatively, the differences in volatile production might have been too small to be detected in our experimental setup.

\section{Priming for enhanced defense.}

Over the past decades, there has been increasing evidence demonstrating that plants can be primed for more efficient activation of cellular defense responses upon challenge, resulting in enhanced resistance to various biotic or abiotic stresses (Conrath et al. 2006). The primed state can be activated in various ways, such as upon infection by necrotizing pathogens, colonization of plant roots by beneficial microbes (e.g., rhizobacteria and mycorrhizal fungi), insect herbivory, or specific natural or synthetic compounds such as $\beta$-aminobutyric acid, SA, and BTH (Conrath et al. 2006; Frost et al. 2008; Pieterse and Dicke 2007). Each inducer of the primed state primes the plant for a specific set of genes. For instance, rhizobacteriamediated ISR is associated with priming for enhanced JA and ET-responsive gene expression, whereas low doses of the SAmimic BTH prime the plant for enhanced SA-responsive gene expression. Hence, the outcome of the defense reaction depends on the set of genes that is activated by the attacker encountered. Priming of the SA response is not expected to affect pathogens and insects that solely activate JA and ET-dependent defenses, whereas priming of the JA response is not expected to affect attackers that solely activate SA-dependent defenses. The potential impact of the priming phenomenon in induced pathogen and insect resistance highlights the complexity of the defense signaling interactions between plants, pathogens, and insect herbivores.

\section{MATERIALS AND METHODS}

\section{Plant growth conditions.}

Arabidopsis thaliana accession Col-0, the JA-signaling mutant coil-16 (Ellis and Turner 2002), and transgenic NahG plants harboring the bacterial nahG gene (Delaney et al. 1994) were grown from seeds in quartz sand. Homozygous coil-1 mutants were selected on plates containing $50 \mu \mathrm{M}$ JA as described previously (Xie et al. 1998). Mutant coil-16 was used to test the performance of $P$. rapae, whereas coil-1 was used for the $S$. exigua growth assays. Both coil mutants behave similarly in terms of insect resistance (data not 
shown). Two-week-old seedlings were transplanted into 60$\mathrm{ml}$ pots containing a sand-potting soil mixture that had been autoclaved twice for $20 \mathrm{~min}$ with a 24-h interval. Plants were cultivated in a growth chamber with an 8-h-day $\left(200 \mu \mathrm{E} \mathrm{m} \mathrm{m}^{-2}\right.$ $\mathrm{s}^{-1}$ at $\left.24 \pm 1^{\circ} \mathrm{C}\right)$ and 16 -h-night $\left(20 \pm 1^{\circ} \mathrm{C}\right)$ cycle at $70 \%$ relative humidity $(\mathrm{RH})$ for 3 to 5 more weeks, depending on the experiment. During the whole experiment, all plants remained in the vegetative stage. Plants were watered on alternate days and, once a week, were supplied with a modified half-strength Hoagland's nutrient solution, as described (Hoagland and Arnon 1938).

\section{Cultivation of microorganisms.}

A nonpathogenic, rifampicin-resistant strain, Pseudomonas fluorescens WCS417r, was used for induction of ISR (Pieterse et al. 1996). The strain was grown for $24 \mathrm{~h}$ at $28 \pm 1^{\circ} \mathrm{C}$ on King's medium B (KB) agar plates (King et al. 1954) containing the appropriate antibiotics, as described previously (Van Wees et al. 1997). An avirulent strain of Pseudomonas syringae pv. tomato DC3000 with the plasmid pV288 carrying the avirulence gene avrRpt2 (Kunkel et al. 1993) was used for SAR induction. Pseudomonas syringae pv. tomato DC3000 (avrRpt2) bacteria were grown overnight at $28 \pm 1^{\circ} \mathrm{C}$ in liquid $\mathrm{KB}$ medium supplemented with $25 \mathrm{mg}$ of kanamycin per milliliter to select for the plasmid. After centrifugation for $10 \mathrm{~min}$ at $5,000 \times g$, the bacterial cells were resuspended in $10 \mathrm{mM}$ $\mathrm{MgSO}_{4}$ to a final density of $10^{7} \mathrm{CFU} \mathrm{ml} \mathrm{m}^{-1}$.

\section{Insect rearing.}

Pieris rapae (small cabbage white butterfly) was reared on Brussels sprouts plants (Brassica oleracea gemmifera cv. Icarus) in a climate chamber $\left(21 \pm 1^{\circ} \mathrm{C}, 50\right.$ to $70 \% \mathrm{RH}, 16$-hlight and 8-h-dark cycle), as described previously (Van Poecke et al. 2001). First-instar (L1) larvae hatched on Brussels sprouts plants were used in all experiments.

Spodoptera exigua (beet armyworm) was reared on an artificial diet in a climate chamber $\left(27 \pm 2^{\circ} \mathrm{C}, 70\right.$ to $80 \% \mathrm{RH}, 16-\mathrm{h}$ light and 8-h-dark cycle) according to Smits and associates (1986). In all experiments, the L1 larvae used were hatched in a climate room $\left(23 \pm 1{ }^{\circ} \mathrm{C}, 50\right.$ to $70 \% \mathrm{RH}, 16$-h-light and 8-hdark cycle) and were supplied with Brussels sprouts plants.

The parasitoid Cotesia rubecula was reared on $P$. rapae larvae on Brussels sprouts plants in a glasshouse $\left(25 \pm 5^{\circ} \mathrm{C}, 50\right.$ to $70 \% \mathrm{RH}, 16$-h-light and 8-h-dark cycle). The pupae were collected and transferred to a climate room $\left(23 \pm 1^{\circ} \mathrm{C}, 50\right.$ to $70 \%$ RH, 16-h-light and 8-h-dark cycle). The emerging parasitoid wasps were provided with water and honey. Adult female wasps without oviposition experience were selected for the experiments, as described previously (Van Poecke et al. 2001).

\section{Microbially induced resistance.}

Induction of ISR and SAR was performed as described (Pieterse et al. 1996). Briefly, to induce ISR, a suspension of Pseudomonas fluorescens WCS417r rhizobacteria was mixed thoroughly through the soil to a final density of $5 \times 10^{7} \mathrm{CFU}$ per gram of soil. Subsequently, 2-week-old seedlings were transferred to the soil and allowed to grow for another 3 to 5 weeks. For induction of SAR, three lower leaves of 5- to 7 week-old plants were pressure infiltrated with a suspension of Pseudomonas syringae pv. tomato DC3000 (avrRpt2) at $10^{7}$ $\mathrm{CFU} \mathrm{ml} \mathrm{m}^{-1}$. When used for parasitoid two-choice flight experiments, the infiltrated leaves of SAR-induced plants were removed after 3 days, as were the three corresponding leaves of uninduced or ISR-induced plants. Expression of ISR and SAR was routinely checked using virulent Pseudomonas syringae pv. tomato DC3000 as a challenging pathogen as described (Pieterse et al. 1996).
Herbivore development bioassays.

Using a fine paint brush, single L1 larvae of $P$. rapae or $S$. exigua were transferred to individual 6- to 7-week-old Arabidopsis plants ( $n=20$ to 25 ). Each soil-grown plant was confined in a Magenta GA-7 vessel (Sigma-Aldrich, Zwijndrecht, The Netherlands) with an insect-proof mesh lid. The Magenta boxes were kept in a climate room $\left(23 \pm 1{ }^{\circ} \mathrm{C}, 50 \% \mathrm{RH}, 16-\mathrm{h}-\right.$ light and 8-h-dark cycle). The caterpillars were weighed to the nearest $0.1 \mathrm{mg}$ on a microbalance (Sartorius AC211P). The time until pupation was determined by scoring the day on which the caterpillars pupated ( $P$. rapae) or the day the larvae moved into the soil in order to pupate $(S$. exigua). Once the first plant was eaten, a second plant was supplied to all caterpillars on the same day. Usually, two plants were enough for the caterpillars to reach pupation. Between replicate experiments, average larval weights varied. This is typical for insect bioassays, because for each experiment, different egg batches from different mothers are used. Nonparametric tests were performed to analyze weights of larvae that survived until pupation (Kruskal-Wallis test followed by Mann-Whitney U test for pair-wise comparisons). One-way analysis of variance with a least significant difference post hoc test was performed to analyze the time to pupation. The data were analyzed in SPSS 11.5 for Windows.

\section{RNA extraction and Northern blot analysis.}

Total RNA was extracted as described (Van Wees et al. 1999) from shoots of 5- to 7-week-old plants that were either uninduced or expressing ISR or SAR. Leaf material was harvested 24,48 , or $72 \mathrm{~h}$ after challenge with five L1 P. rapae or $10 \mathrm{~L} 1 \mathrm{~S}$. exigua larvae. For Northern blot analysis, $15 \mu \mathrm{g}$ of RNA were denatured using glyoxal and dimethyl sulfoxide (Sambrook et al. 1989). Subsequently, the denatured RNA was separated by electrophoresis on a $1.5 \%$ agarose gel and was blotted onto a Hybond- $\mathrm{N}^{+}$membrane (Amersham Biosciences, Roosendaal, The Netherlands) by capillary transfer. The electrophoresis and blotting buffer consisted of 10 and $25 \mathrm{mM}$ sodium phosphate ( $\mathrm{pH} 7.0$ ), respectively. Gene-specific probes for $P D F 1.2$ and $H E L$ were used for hybridization as described previously (Van Wees et al. 1999). The Arabidopsis Genome Initiative numbers for the genes studied are At5g44420 (PDF 1.2) and At3g04720 (HEL). A probe for $18 \mathrm{~S}$ ribosomal RNA, derived from an Arabidopsis cDNA clone (Pruitt and Meyerowitz 1986), was used to check for equal loading. For microarray analysis, RNA was isolated as described (Reymond et al. 2004) and further purified using an RNeasy mini kit (Qiagen, Basel, Switzerland).

\section{Microarray experiments and data analysis.}

Microarray experiments were performed with probes from three independent biological replicates and a custom-made microarray with 279 Arabidopsis cDNAs representing 111 insectresponsive genes, 17 housekeeping genes, and 94 genes previously demonstrated to be associated with plant defense (Bodenhausen and Reymond 2007). Preparation of DNA, printing of cDNA microarrays, labeling of RNA probes, and hybridization of microarrays was carried out as described previously (Bodenhausen and Reymond 2007; Reymond et al. 2004). RNAs from uninfested plants were labeled with Cy3 and RNAs from infested plants were labeled with Cy5. After hybridization, microarrays were scanned with a ScanArray 4000 (Packard BioScience SA, Zurich, Switzerland). Photomultiplier and laser power settings were adjusted so that the expression ratio of housekeeping genes was as close to 1.0 as possible and signal intensities were below saturation of the scanner. The average fluorescence intensity for each fluor and for each gene was determined using the ImaGene program 
(BioDiscovery Inc., Los Angeles, CA, U.S.A.). Median background fluorescence signal around each gene spot was subtracted from each spot. To adjust signal intensities between $\mathrm{Cy} 3$ and Cy5 channels, a normalization factor was calculated from the expression ratios of 17 housekeeping genes so that the median expression ratio of these genes was equal to 1.0. This normalization factor was then applied to all backgroundcorrected Cy5 intensities. Signal values $<1,000$ (two to three times the average background intensity) were raised to 1,000 to avoid extreme expression ratios. Normalized signal intensities were used to calculate expression ratios. To account for individual variability of transcript levels between groups of untreated plants, a control hybridization was performed using two independent samples obtained from plants harvested the same day. To calculate $P$ values, a Student's $t$ test (two sample hypothesis, equal variance) was conducted between $\log _{2}$-transformed expression ratios from control versus control experiments and $\log _{2}$-transformed ratios from control versus treated experiments. To address the issue of multiple comparisons, a false-discovery rate (FDR) was calculated using the method of Storey and Tibshirani (2003). This method computes a $q$ value for each gene, using the distribution of $P$ values of all measurements. For data with $S$. exigua, the FDR at $P=0.05$ was $3.2 \%$ (uninfested versus infested) and $3.6 \%$ (ISR, uninfested versus ISR, infested). For data with $P$. rapae, the FDR at $P=$ 0.05 was $1.6 \%$ (uninfested versus infested) and $3.5 \%$ (ISR, uninfested versus ISR, infested). All microarray data have been deposited in ArrayExpress under accession number E-MEXP1485.

To identify insect-responsive genes, the following treatments were compared on the microarrays: i) uninfested control plants vs. $S$. exigua-infested control plants, ii) uninfested ISR plants vs. $S$. exigua-infested ISR plants, iii) uninfested control plants vs. $P$. rapae-infested control plants, and iv) uninfested ISR plants vs. $P$. rapae-infested ISR plants. All four comparisons were performed with RNA probes that were derived from plant material of three independent biological replicates. Uninfested and infested plant material was harvested simultaneously $48 \mathrm{~h}$ after challenge with the insect herbivores.

To identify genes of which the expression was substantially affected by insect herbivory, two selection criteria were applied: i) the change in gene expression should be statistically significant according to the Student's $t$ test on the $\log _{2^{-}}$ transformed expression ratios (two sample hypothesis, equal variance; $P<0.05$ ), and ii) the changes should be above the level of twofold. This twofold cut-off value was previously shown for this microarray to be well above the variability produced by biological and technical replicates (Reymond et al. 2004). Although statistically significant changes in gene expression below the threshold level of twofold may be biologically relevant, we have chosen to disregard all changes below this threshold level to limit the number of nonrobust positives.

To identify ISR-primed genes among the selected set of insect-responsive genes, the genes that showed a statistically significant change in herbivore-infested ISR-expressing plants over herbivore-infested control plants were selected (Student's $t$ test; $P<0.05$ ). In addition the insect-responsive genes (that already passed selection criteria $i$ and ii) that showed a $>1.5$ fold change in herbivore-invested ISR-expressing plants over herbivore-infested control plants in more than two of the three biological replicates were selected. This priming cut-off value is based on previous quantitative expression data of genes that showed a robust primed expression pattern after pathogen attack (Verhagen et al. 2004). Normalized raw signal intensities of the 12 microarray experiments are given in Supplemental Table S3.

\section{Parasitoid two-choice flight experiments.}

Parasitoid two-choice flight experiments were performed in a wind-tunnel setup $\left(25 \pm 5^{\circ} \mathrm{C}, 50\right.$ to $\left.70 \% \mathrm{RH}, 13 \mu \mathrm{E} \mathrm{m}^{-2} \mathrm{~s}^{-1}\right)$ with an air flow of $0.2 \mathrm{~m} \mathrm{~s}^{-1}$ as described by Geervliet and associates (1994). The setup was used as described (Van Poecke et al. 2001) with 15 5- to 7-week-old Arabidopsis plants per odor source. Uninduced, ISR-, or SAR-expressing plants were infested with L1 larvae using a fine paint brush. Five L1 $P$. rapae larvae per plant were allowed to feed for $24 \mathrm{~h}$. S. exigua larvae were smaller and caused less damage than $P$. rapae larvae. Therefore, $10 \mathrm{~L} 1 \mathrm{~S}$. exigua larvae per plant were allowed to feed for $72 \mathrm{~h}$. The flight behavior of the parasitoid wasp C. rubecula was observed. First landings on one of the odor sources were recorded as "choice," whereas first landings elsewhere in the experimental setup or no flight within 10 min were noted as "no-choice." Per experimental day, three (no damage test) or four (caterpillar-damage test) odor sources were compared in pair-wise combinations. Per odor combination, an equal number of wasps, either six or eight, were tested. Moreover, the position of the two odor sources was exchanged after testing half of the number of parasitoids per combination to avoid positional effects on the behavior of the wasps. Chi-square tests were used to analyze pair-wise differences in the number of choices between the two odor sources. Differences in the total number of responsive wasps between the different odor combinations were determined using a contingency table.

\section{Damage analysis.}

For each two-choice flight experiment, total damage caused by caterpillar feeding was determined for five plants per treatment per day. Total leaves were photocopied and subsequently scanned with a Sony black and white CCD camera type XC77CE (frame size $752 \times 574 ; 256$ gray levels). Image analysis was performed using the KS400 version 3.0 software service pack 9 (Carl Zeiss Vision, Oberkochen, Germany) to quantify the total size of the damaged leaf area.

\section{ACKNOWLEDGMENTS}

We gratefully acknowledge W. van Zaanen, J. Mandersloot, A. LéonReyes, H. Brouwer, and M. Terlou for technical assistance and L. Koopman, F. van Aggelen, and A. Gidding for insect rearing. This research was supported, in part, by grants $811.36 .004,813.06 .002$, and 865.04 .002 from the Earth and Life Sciences Foundation (ALW), which is subsidized by the Netherlands Organization of Scientific Research (NWO), and by a genomics grant from the University of Lausanne.

\section{LITERATURE CITED}

Agrawal, A. A., and Kurashige, N. S. 2003. A role for isothiocyanates in plant resistance against the specialist herbivore Pieris rapae. J. Chem. Ecol. 29:1403-1415.

Agrawal, A. A., Strauss, S. Y., and Stout, M. J. 1999. Costs of induced responses and tolerance to herbivory in male and female fitness components of wild radish. Evolution 53:1093-1104.

Ament, K., Kant, M. R., Sabelis, M. W., Haring, M. A., and Schuurink, R. C. 2004. Jasmonic acid is a key regulator of spider mite-induced volatile terpenoid and methyl salicylate emission in tomato. Plant Physiol. 135:2025-2037.

Arimura, G., Ozawa, R., Shimoda, T., Nishioka, T., Boland, W., and Takabayashi, J. 2000. Herbivory-induced volatiles elicit defence genes in lima bean. Nature 406:512-515.

Arondel, V., Vergnolle, C., Cantrel, C., and Kader, J. C. 2000. Lipid transfer proteins are encoded by a small multigene family in Arabidopsis thaliana. Plant Sci. 157:1-12.

Bell, E., Creelman, R. A., and Mullet, J. E. 1995. A chloroplast lipoxygenase is required for wound-induced accumulation of jasmonic acid in Arabidopsis. Proc. Natl. Acad. Sci. U.S.A. 92:8675-8679.

Bodenhausen, N., and Reymond, P. 2007. Signaling pathways controlling induced resistance to insect herbivores in Arabidopsis. Mol. PlantMicrobe Interact. 20:1406-1420. 
Bostock, R. M. 2005. Signal crosstalk and induced resistance: Straddling the line between cost and benefit. Annu. Rev. Phytopathol. 43:545-580.

Chini, A., Fonseca, S., Fernandez, G., Adie, B., Chico, J. M., Lorenzo, O., Garcia-Casado, G., Lopez-Vidriero, I., Lozano, F. M., Ponce, M. R., Micol, J. L., and Solano, R. 2007. The JAZ family of repressors is the missing link in jasmonate signalling. Nature 448:666-671.

Chung, H. S., Koo, A. J. K., Gao, X., Jayanty, S., Thines, B., Jones, A. D. and Howe, G. A. 2008. Regulation and function of Arabidopsis JASMONATE ZIM-domain genes in response to wounding and herbivory. Plant Physiol. 146:952-964.

Cipollini, D., Enright, S., Traw, M. B., and Bergelson, J. 2004. Salicylic acid inhibits jasmonic acid-induced resistance of Arabidopsis thaliana to Spodoptera exigua. Mol. Ecol. 13:1643-1653.

Conrath, U., Pieterse, C. M. J., and Mauch-Mani, B. 2002. Priming in plant-pathogen interactions. Trends Plant Sci. 7:210-216.

Conrath, U., Beckers, G. J. M., Flors, V., García-Agustín, P., Jakab, G., Mauch, F., Newman, M.-A., Pieterse, C. M. J., Poinssot, B., Pozo, M. J., Pugin, A., Schaffrath, U., Ton, J., Wendehenne, W., Zimmerli, L., and Mauch-Mani, B. 2006. Priming: Getting ready for battle. Mol. Plant-Microbe Interact. 19:1062-1071.

Cui, J., Jander, G., Racki, L. R., Kim, P. D., Pierce, N. E., and Ausubel, F. M. 2002. Signals involved in Arabidopsis resistance to Trichoplusia ni caterpillars induced by virulent and avirulent strains of the phytopathogen Pseudomonas syringae. Plant Physiol. 129:551-564.

Cui, J., Bahrami, A. K., Pringle, E. G., Hernandez-Guzman, G., Bender, C. L., Pierce, N. E., and Ausubel, F. M. 2005. Pseudomonas syringae manipulates systemic plant defenses against pathogens and herbivores. Proc. Natl. Acad. Sci. U.S.A. 102:1791-1796.

De Boer, J. G., and Dicke, M. 2004. The role of methyl salicylate in prey searching behavior of the predatory mite Phytoseiulus persimilis. J. Chem. Ecol. 30:255-271.

De Vos, M., Van Zaanen, W., Koornneef, A., Korzelius, J. P., Dicke, M., Van Loon, L. C., and Pieterse, C. M. J. 2006. Herbivore-induced resistance against microbial pathogens in Arabidopsis. Plant Physiol. 142:352-363.

De Vos, M., Van Oosten, V. R., Van Poecke, R. M., Van Pelt, J. A., Pozo, M. J., Mueller, M. J., Buchala, A. J., Metraux, J. P., Van Loon, L. C. Dicke, M., and Pieterse, C. M. 2005. Signal signature and transcriptome changes of Arabidopsis during pathogen and insect attack. Mol. PlantMicrobe Interact. 18:923-937.

Delaney, T. P., Uknes, S., Vernooij, B., Friedrich, L., Weymann, K. Negrotto, D., Gaffney, T., Gut-Rella, M., Kessmann, H., Ward, E., and Ryals, J. 1994. A central role of salicylic acid in plant disease resistance. Science 266:1247-1250.

Dicke, M. 1999. Evolution of induced indirect defence of plants. Pagse 62 88 in: The Ecology and Evolution of Inducible Defenses. R. Tollrian and C. D. Harvell, eds. Princeton University Press, Princeton, NJ. U.S.A.

Dicke, M., and Van Poecke, R. M. P. 2002. Signaling in plant-insect interactions: Signal transduction in direct and indirect plant defence. Pages 289-316 in: Plant Signal Transduction: Frontiers in Molecular Biology. D.Scheel and C. Wasternack, eds. Oxford University Press, Oxford.

Dicke, M., Gols, R., Ludeking, D., and Posthumus, M. A. 1999. Jasmonic acid and herbivory differentially induce carnivore-attracting plant volatiles in lima bean plants. J. Chem. Ecol. 25:1907-1922.

Durrant, W. E., and Dong, X. 2004. Systemic acquired resistance. Annu. Rev. Phytopathol. 42:185-209.

Ellis, C., and Turner, J. G. 2002. A conditionally fertile coil allele indicates cross-talk between plant hormone signaling pathways in Arabidopsis thaliana seeds and young seedlings. Planta 215:549-556.

Ellis, C., Karafyllidis, L., and Turner, J. G. 2002. Constitutive activation of jasmonate signaling in Arabidopsis mutant correlates with enhanced resistance to Erysiphe cichoracearum, Pseudomonas syringae, and Myzus persicae. Mol. Plant-Microbe Interact. 15:1025-1030.

Engelberth, J., Alborn, H. T., Schmelz, E. A., and Tumlinson, J. H. 2004 Airborne signals prime plants against insect herbivore attack. Proc. Natl. Acad. Sci. U.S.A. 101:1781-1785

Felton, G. W., and Korth, K. L. 2000. Trade-offs between pathogen and herbivore resistance. Curr. Opin. Plant Biol. 3:309-314

Frost, C. J., Mescher, M. C., Carlson, J. E., and De Moraes, C. M. 2008 Plant defense priming against herbivores: Getting ready for a different battle. Plant Physiol. 146:818-824.

García-Olmedo, F., Molina, A., Segura, A., and Moreno, M. 1995. The defensive role of nonspecific lipid-transfer proteins in plants. Trends Microbiol. 3:72-74.

Geervliet, J. B. F., Vet, L. E. M., and Dicke, M. 1994. Volatiles from damaged plants as major cues in long-range host-searching by the specialist parasitoid Cotesia rubecula. Entomol. Exp. Appl. 73:289-297.

Glazebrook, J. 2001. Genes controlling expression of defense responses in Arabidopsis-2001 status. Curr. Opin. Plant Biol. 4:301-308.
Glazebrook, J. 2005. Contrasting mechanisms of defense against biotrophic and necrotrophic pathogens. Annu. Rev. Phytopathol. 43:205-227.

Hoagland, D. R., and Arnon, D. I. 1938. The water culture method for growing plants without soil. Calif. Agric. Exp. Stn. Bull. 347:36-39.

Howe, G. A. 2004. Jasmonates as signals in the wound response. J. Plant Growth Regul. 23:223-237.

Kader, J. C. 1997. Lipid-transfer proteins: A puzzling family of plant proteins. Trends Plant Sci. 2:66-70.

Kant, M. R., Ament, K., Sabelis, M. W., Haring, M. A., and Schuurink, R. C. 2004. Differential timing of spider mite-induced direct and indirect defenses in tomato plants. Plant Physiol. 135:483-495.

Kessler, A., and Baldwin, I. T. 2002. Plant responses to insect herbivory: The emerging molecular analysis. Annu. Rev. Plant Biol. 53:299-328.

Kessler, A., Halitschke, R., Diezel, C., and Baldwin, I. T. 2006. Priming of plant defense responses in nature by airborne signaling between $\mathrm{Ar}$ temisia tridentata and Nicotiana attenuata. Oecologia 148:280-292.

King, E. O., Ward, M. K., and Raney, D. E. 1954. Two simple media for the demonstration of phycocyanin and fluorescin. J. Lab. Clin. Med. 44:301-307.

Konno, K., Hirayama, C., Nakamura, M., Tateishi, K., Tamura, Y., Hattori, M., and Kohno, K. 2004. Papain protects papaya trees from herbivorous insects: Role of cysteine proteases in latex. Plant J. 37:370-378.

Koornneef, A., and Pieterse, C. M. J. 2008. Cross-talk in defense signaling. Plant Physiol. 146:839-844.

Kunkel, B. N., Bent, A. F., Dahlbeck, D., Innes, R. W., and Staskawicz, B. J. 1993. RPS2, an Arabidopsis disease resistance locus specifying recognition of Pseudomonas syringae strains expressing the avirulence gene AvrRpt2. Plant Cell 5:865-875.

Maldonado, A. M., Doerner, P., Dixon, R. A., Lamb, C. J., and Cameron, R. K. 2002. A putative lipid transfer protein involved in systemic resistance signalling in Arabidopsis. Nature 419:399-403.

McConn, J., Creelman, R. A., Bell, E., Mullet, J. E., and Browse, J. 1997. Jasmonate is essential for insect defense in Arabidopsis. Proc. Natl. Acad. Sci. U.S.A. 94:5473-5477.

Mewis, I., Appel, H. M., Hom, A., Raina, R., and Schultz, J. C. 2005. Major signaling pathways modulate Arabidopsis glucosinolate accumulation and response to both phloem-feeding and chewing insects. Plant Physiol. 138:1149-1162.

Mewis, I., Tokuhisa, J. G., Schultz, J. C., Appel, H. M., Ulrichs, C., and Gershenzon, J. 2006. Gene expression and glucosinolate accumulation in Arabidopsis thaliana in response to generalist and specialist herbivores of different feeding guilds and the role of defense signaling pathways. Phytochemistry 67:2450-2462.

Mur, L. A. J., Kenton, P., Atzorn, R., Miersch, O., and Wasternack, C. 2006. The outcomes of concentration-specific interactions between salicylate and jasmonate signaling include synergy, antagonism, and oxidative stress leading to cell death. Plant Physiol. 140:249-262.

Paschold, A., Halitschke, R., and Baldwin, I. T. 2006. Using 'mute' plants to translate volatile signals. Plant J. 45:275-291.

Pieterse, C. M. J., and Dicke, M. 2007. Plant interactions with microbes and insects: From molecular mechanisms to ecology. Trends Plant Sci. 12:564-569.

Pieterse, C. M. J., Ton, J., and Van Loon, L. C. 2001. Cross-talk between plant defence signalling pathways: Boost or burden? AgBiotechNet 3:ABN 068. Published online.

Pieterse, C. M. J., Van Wees, S. C. M., Hoffland, E., Van Pelt, J. A., and Van Loon, L. C. 1996. Systemic resistance in Arabidopsis induced by biocontrol bacteria is independent of salicylic acid accumulation and pathogenesis-related gene expression. Plant Cell 8:1225-1237.

Pieterse, C. M. J., Van Wees, S. C. M., Ton, J., Van Pelt, J. A., and Van Loon, L. C. 2002. Signalling in rhizobacteria-induced systemic resistance in Arabidopsis thaliana. Plant Biol. 4:535-544.

Pieterse, C. M. J., Van Wees, S. C. M., Van Pelt, J. A., Knoester, M., Laan, R., Gerrits, H., Weisbeek, P. J., and Van Loon, L. C. 1998. A novel signaling pathway controlling induced systemic resistance in Arabidopsis. Plant Cell 10:1571-1580.

Pruitt, R. E., and Meyerowitz, E. M. 1986. Characterization of the genome of Arabidopsis thaliana. J. Mol. Biol. 187:169-183.

Reymond, P., and Farmer, E. E. 1998. Jasmonate and salicylate as global signals for defense gene expression. Curr. Opin. Plant Biol. 1:404411.

Reymond, P., Bodenhausen, N., Van Poecke, R. M. P., Krishnamurthy, V., Dicke, M., and Farmer, E. E. 2004. A conserved transcriptional pattern in response to a specialist and a generalist herbivore. Plant Cell 16:3132-3147.

Sambrook, J., Fritsch, E. F., and Maniatis, T. 1989. Molecular Cloning: A Laboratory Manual. Cold Spring Harbor Laboratory Press, Cold Spring Harbor, NY, U.S.A.

Segura, A., Moreno, M., and García-Olmedo, F. 1993. Purification and antipathogenic activity of lipid transfer proteins (LTPs) from the leaves 
of Arabidopsis and spinach. FEBS (Fed. Eur. Biochem. Soc.) Lett. 332:243-246.

Smits, P. H., Van de Vrie, M., and Vlak, J. M. 1986. Oviposition of beet armyworm (Lepidoptera: Noctuidae) on greenhouse crops. Environ. Entomol. 15:1189-1191.

Spoel, S. H., Johnson, J. S., and Dong, X. 2007. Regulation of tradeoffs between plant defenses against pathogens with different lifestyles. Proc. Natl. Acad. Sci. U.S.A. 104:18842-18847.

Spoel, S. H., Koornneef, A., Claessens, S. M. C., Korzelius, J. P., Van Pelt, J. A., Mueller, M. J., Buchala, A. J., Métraux, J.-P., Brown, R., Kazan, K., Van Loon, L. C., Dong, X., and Pieterse, C. M. J. 2003. NPR1 modulates cross-talk between salicylate- and jasmonate-dependent defense pathways through a novel function in the cytosol. Plant Cell 15:760-770

Stintzi, A., Weber, H., Reymond, P., Browse, J., and Farmer, E. E. 2001. Plant defense in the absence of jasmonic acid: The role of cyclopentenones. Proc. Natl. Acad. Sci. U.S.A. 98:12837-12842.

Storey, J. D., and Tibshirani, R. 2003. Statistical significance for genomewide studies. Genome Biol. 100:9440-9445.

Stotz, H. U., Koch, T., Biedermann, A., Weniger, K., Boland, W., and Mitchell-Olds, T. 2002. Evidence for regulation of resistance in Arabidopsis to Egyptian cotton worm by salicylic and jasmonic acid signaling pathways. Planta 214:648-652.

Stout, M. J., Thaler, J. S., and Thomma, B. P. H. J. 2006. Plant-mediated interactions between pathogenic microorganisms and herbivorous arthropods. Annu. Rev. Entomol. 51:663-689.

Takabayashi, J., and Dicke, M. 1996. Plant-carnivore mutualism through herbivore-induced carnivore attractants. Trends Plant Sci. 1:109-113.

Thaler, J. S., Owen, B., and Higgins, V. J. 2004. The role of the jasmonate response in plant susceptibility to diverse pathogens with a range of lifestyles. Plant Physiol. 135:530-538.

Thines, B., Katsir, L., Melotto, M., Niu, Y., Mandaokar, A., Liu, G., Nomura, K., He, S. Y., Howe, G. A., and Browse, J. 2007. JAZ repressor proteins are targets of the SCF(COI1) complex during jasmonate signalling 448:661-665.

Thomma, B. P. H. J., Penninckx, I. A. M. A., Broekaert, W. F., and Cammue, B. P. A. 2001. The complexity of disease signaling in Arabidopsis. Curr. Opin. Immunol. 13:63-68.

Ton, J., Van Pelt, J. A., Van Loon, L. C., and Pieterse, C. M. J. 2002. Differential effectiveness of salicylate-dependent and jasmonate/ethylenedependent induced resistance in Arabidopsis. Mol. Plant-Microbe Interact. 15:27-34.

Ton, J., D’Alessandro, M., Jourdie, V., Jakab, G., Karlen, D., Held, M., Mauch-Mani, B., and Turlings, T. C. J. 2006. Priming by air-borne signals boosts direct and indirect resistance in maize. Plant J. 49:16-26.

Truman, W., Bennett, M. H., Kubigsteltig, I., Turnbull, C., and Grant, M. 2007. Arabidopsis systemic immunity uses conserved defense signaling pathways and is mediated by jasmonates. Proc. Natl. Acad. Sci. U.S.A. 104:1075-1080.

Turlings, T. C. J., Loughrin, J. H., McCall, P. J., Rose, U. S. R., Lewis, W. J., and Tumlinson, J. H. 1995. How caterpillar-damaged plants protect themselves by attracting parasitic wasps. Proc. Natl. Acad. Sci. U.S.A. 92:4169-4174.

Van der Ent, S., Verhagen, B. W. M., Van Doorn, R., Bakker, D., Verlaan, M. G., Pel, M. J. C., Joosten, R. G., Proveniers, M. C. G., Van Loon, L. C., Ton, J., and Pieterse, C. M. J. 2008. MYB72 is required in early signaling steps of rhizobacteria-induced systemic resistance in Arabidopsis. Plant Physiol. 146:1293-1304.

Van Loon, J. J. A., De Boer, J. G., and Dicke, M. 2000. Parasitoid-plant mutualism: Parasitoid attack of herbivore increases plant reproduction. Entomol. Exp. Appl. 97:219-227.

Van Loon, L. C. 2000. Systemic induced resistance. Pages 521-574 in: Mechanisms of Resistance to Plant Diseases. A. J., Slusarenko, R. S. S.
Fraser, and L. C. Van Loon, eds. Kluwer Academic Publishers, Dordrecht, The Netherlands.

Van Loon, L. C., Bakker, P. A. H. M., and Pieterse, C. M. J. 1998. Systemic resistance induced by rhizosphere bacteria. Annu. Rev. Phytopathol. 36:453-483.

Van Loon, L. C., Rep, M., and Pieterse, C. M. J. 2006. Significance of inducible defense-related proteins in infected plants. Annu. Rev. Phytopathol. 44:135-162.

Van Poecke, R. M. P., and Dicke, M. 2002. Induced parasitoid attraction by Arabidopsis thaliana: Involvement of the octadecanoid and the salicylic acid pathway. J. Exp. Bot. 53:1793-1799.

Van Poecke, R. M. P., and Dicke, M. 2004. Indirect defence of plants against herbivores: Using Arabidopsis thaliana as a model plant. Plant Biol. 6:387-401.

Van Poecke, R. M. P., Posthumus, M. A., and Dicke, M. 2001. Herbivoreinduced volatile production by Arabidopsis thaliana leads to attraction of the parasitoid Cotesia rubecula: Chemical, behavioral, and gene-expression analysis. J. Chem. Ecol. 27:1911-1928.

Van Poecke, R. M. P., Roosjen, M., Pumarino, L., and Dicke, M. 2003. Attraction of the specialist parasitiod Cotesia rubecula to Arabidopsis thaliana infested by host or non-host herbivore species. Entomol. Exp. Appl. 107:229-236.

Van Wees, S. C. M., Luijendijk, M., Smoorenburg, I., Van Loon, L. C., and Pieterse, C. M. J. 1999. Rhizobacteria-mediated induced systemic resistance (ISR) in Arabidopsis is not associated with a direct effect on expression of known defense-related genes but stimulates the expression of the jasmonate-inducible gene Atvsp upon challenge. Plant Mol. Biol. 41:537-549.

Van Wees, S. C. M., Pieterse, C. M. J., Trijssenaar, A., Van't Westende, Y. A. M., Hartog, F., and Van Loon, L. C. 1997. Differential induction of systemic resistance in Arabidopsis by biocontrol bacteria. Mol. PlantMicrobe Interact. 10:716-724.

Verhagen, B. W. M., Glazebrook, J., Zhu, T., Chang, H.-S., Van Loon, L. C., and Pieterse, C. M. J. 2004. The transcriptome of rhizobacteriainduced systemic resistance in Arabidopsis. Mol. Plant-Microbe Interact. 17:895-908.

Von Dahl, C. C., and Baldwin, I. T. 2007. Deciphering the role of ethylene in plant-herbivore interactions. J. Plant Growth Regul. 26:201-209.

Wittstock, U., Agerbirk, N., Stauber, E. J., Olsen, C. E., Hippler, M., Mitchell-Olds, T., Gershenzon, J., and Vogel, H. 2004. Successful herbivore attack due to metabolic diversion of a plant chemical defense. Proc. Natl. Acad. Sci. U.S.A. 101:4859-4864.

Xie, D. X., Feys, B. F., James, S., Nieto-Rostro, M., and Turner, J. G. 1998. COI1: An Arabidopsis gene required for jasmonate-regulated defense and fertility. Science 280:1091-1094.

Yamada, K., Matsushima, R., Nishimura, M., and Hara-Nishimura, I. 2001. A slow maturation of a cysteine protease with a granulin domain in the vacuoles of senescing Arabidopsis leaves. Plant Physiol. 127:1626-1634.

Yano, S., and Ohsaki, N. 1993. The phenology and intrinsic quality of wild crucifers that determine the community structure of their herbivorous insects. Res. Pop. Ecol. 35:151-170.

Zarate, S. I., Kempema, L. A., and Walling, L. L. 2007. Silverleaf whitefly induces salicylic acid defenses and suppresses effectual jasmonic acid defenses. Plant Physiol. 143:866-875.

Zehnder, G. W., Murphy, J. F., Sikora, E. J., and Kloepper, J. W. 2001. Application of rhizobacteria for induced resistance. Eur. J. Plant Pathol. 107:39-50.

\section{AUTHOR RECOMMENDED INTERNET RESOURCE}

ArrayExpress server: www.ebi.ac.uk/arrayexpress 